\title{
Synthesis Parameters of Biodiesel From Frying Oils Wastes
}

\author{
Soulayman Soulayman* and Dayoub Ola
}

Department of Applied Physics, Higher Institute for Applied Sciences and technology (HIAST), Damascus, Syria

\begin{abstract}
This study is devoted to produce biodiesel from recycled wastes frying oils (WFO) using commercial grade chemicals in an attempt to help reducing the cost of biodiesel and pollution coming from WFO. The base - catalyzed transesterification method was applied. The variables affecting the yield and characteristics of the biodiesel produced from WFO were studied. Sodium hydroxide is used as catalyst. Different reaction times, different methanol/WFO volume ratios and different catalyst/WFO weight ratios were used with purpose of achieving the best conditions for biodiesel production A series of experiments were carried out, using methanol/WFO volume ratios from $10 \%$ to $30 \%$ and catalyst/WFO weight ratio from $0.2 \%$ to $0.8 \%$. It was found that in treating WFO which contains $0.12 \%$ of water by weight and having an acid value of $0.52 \mathrm{mg}$ of $\mathrm{KOH} / \mathrm{g}$ of oil, and an iodine value $130.42 \mathrm{gI} / 100 \mathrm{~g}$ of oil, no need in acidic pretreatment. Moreover, it was found that, for WFO with an acidic value of $0.52 \mathrm{mg} \mathrm{KOH} / \mathrm{gWFOs}$, results show that a methanol/WFO volume ratio of $13 \%$ and a catalyst/WFO weight ratio of $0.4 \%$ give the highest yield of methyl esters. A pilot production unit of $4001 /$ day of production capacity was designed and constructed on the basis of laboratory experiments and the process was verified on the pilot scale.
\end{abstract}

(C2019. CBIORE-IJRED. All rights reserved

Keywords: recycled frying oils, biodiesel, transesterification method, commercial chemicals, experiments, pilot station.

Article History: Received October 18 th 2017; Received in revised form May 17 th 2018; Accepted December $8^{\text {th }}$ 2018; Available online

How to Cite This Article: Soulayman, S. and Ola, D. (2019) Synthesis Parameters of Biodiesel From Frying Oils Wastes. Int. Journal of Renewable Energy Development, 8(1), 33-39.

https://doi.org/10.14710/ijred.8.1.33-39

\section{Introduction}

In Syria, thousands litres of fatty wastes are discarded each year into sewage systems. This adds to the cost of treating effluent or pollutes waterways, or is integrated into the food chain through animal feeding, thus becoming a potential cause of human health issues. There are several end-uses for this waste, such as the production of soaps or of energy by anaerobic digestion, thermal cracking (Zaher, 2003), and more recently the production of biodiesel. From a waste management standpoint, producing biodiesel from used cooking oil is environmentally beneficial, since it provides a cleaner way for disposing these products in comparison with what is typically done. Moreover, the fuel thus obtained performs in similar way to fossil fuel, with the advantage of reducing greenhouse emissions because it is a renewable resource. Anyway, a global biofuel economy, with a division of labour favouring the most efficient producers, would be a key boon to developing countries. Their yearround growing seasons and cheap farm labour offer a valuable competitive advantage over colder and high production cost rich countries. Yet, the emerging global market in biofuels is running into political trouble.

Many reviews of biodiesel production processes by transesterification are available, (Ma \& Hanna 1999, Demirbas, 2003, Lotero et al.. 2005, Ferreira, Cardoso \& da Silva, 2012, Gnanaprakasam et al., 2013, Talebian-
Kiakalaieh, Amin, Mazaheri, 2013, Araujo, Andrade, Silva, Dupas, 2013, Alemayehu Gashaw \& Abile Teshita, 2014). However, the use of several low molecular weight alcohols and homogeneous acid and basic catalysts for transesterification has been studied with success over years (Nye, 1983, Peterson\& Scarrah, 1984, Schuchardi, Sercheli \& Vargas, 1998, Khan, 2002). The production of biodiesel continues to be an axis of research for different research groups all over the world (see for example (Dorado et al., 2002 a, Dorado et al., 2002b, Guo \& Leung, 2003, Zhang, Dube, Mclean, and Kates, 2003, Van Gerpen, 2005, Felizardo et al., 2006, Charpe \& Rathod 2011, Puna et al., 2013, Medina-Valtierra \& Ramirez-Ortiz, 2013, Seid Yimer, \& Omprakash Sahu, 2014)).

Basic homogeneous catalysts have surpassed the acid ones, because the reaction is faster and lead to the same yield of transesterification (above 90\% for both) (Schuchardi, Sercheli \& Vargas, 1998). On the other hand, sodium and potassium hydroxides react with the alcohol to give water. This reaction is undesirable, because water can react with triglycerides, fatty acids, or esters in hydrolysis reactions and subsequent saponification (Peterson\& Scarrah, 1984).

In spite of their lower reactivity, sodium and potassium hydroxides can also lead to high reaction yields just by increasing the catalyst quantities. The transesterification reaction reaches its equilibrium state and the transformation accurse essentially by mixing the

\footnotetext{
* Corresponding author: soulayman1952@gmail.com
} 
reactants. The presence of a catalyst accelerates the adjustment of the equilibrium considerably (Ma \& Hanna 1999). The stoichiometric reaction requires 1 mole of triglyceride and 3 mole of alcohol.

This study is intended to consider aspects related to the facility of the production of biodiesel from waste/recycled oils using commercial grade chemicals in an attempt to help reduce the cost of biodiesel and reduce waste and pollution from waste oils. The variables such as methanol to WFO molar ratio, the reaction temperature, the reaction time and the amount of catalyst that affect the yield and characteristics of the WFO based biodiesel were studied. The achieved results were analysed and a set of recommendation was proposed. An educational pilot production unit of 4001/day of production capacity was designed, constructed and exploited on the basis of experimental results.

\section{Materials and Methods}

\subsection{Materials}

This research was carried out at Higher Institute for Applied Sciences and Technology (HIAST), Damascus, Syria during the years 2010-2015. The WFO was collected from HIAST's restaurant. It consisted only of soybean oil. The cooking temperature of the oil varied from 150 to more then $200^{\circ} \mathrm{C}$. The oil was kept at these temperatures for 6 hours per day and was replaced weekly. Because of their low cost, commercial grade chemicals such as methanol and sodium hydroxide $(\mathrm{NaOH})$ were chosen as alcohol and alkaline catalyst for transesterification process. Pure (Merck GR) chemicals were also used but practical differences were not observed. Therefore, all provided results are based on grade commercial chemicals. Moreover, a pilot production unit has been designed and constructed. This unit operates with WFO feedstock and commercial grade chemicals. Fig. 1 describes the processing steps and methods used to produce biodiesel and pure glycerine from WFO with the production capacity of $400 \mathrm{l} /$ day.

\subsection{Frying oil Pre-treatment}

When reacting the WFO, filtration operation is always done to remove any suspended matter. Moreover, in the conventional transesterification of fats/vegetable oils for biodiesel production, free fatty acids and water always produce negative effects, since their presence causes soap formation, consumes catalyst and reduces catalyst effectiveness, all resulting in a low conversion (Kusdiana $\&$ Saka, 2004). The waste frying oil (WFO) pretreatment to remove water was done using primary vacuum pump at $80^{\circ} \mathrm{C}$ and by heating treatment at $110^{\circ} \mathrm{C}$. The treated oil contains $0.12 \mathrm{wt} \%$ of water, an acid value of $0.52 \mathrm{mg}$ of $\mathrm{KOH} / \mathrm{g}$ of oil, and an iodine value of $130.42 \mathrm{gI} / 100 \mathrm{~g}$ of oil. Generally, the synthesis of biodiesel from low quality oils such as WFO containing a low to moderate amount of free fatty acids (FFAs) in addition to moisture and other impurities is challenging due to undesirable side reactions. The pretreatment stages, involving an acid catalyzed pretreatment integrated with water separation, are necessitated to reduce FFAs concentration and water to below threshold limits prior of being processed by standard biodiesel manufacturing. Besides reducing FFAs concentrations, acid catalysts are able to catalyze triglycerides (TG) transesterification, opening the door for the use of acid catalysts to perform simultaneous FFA esterification and TG transesterification.

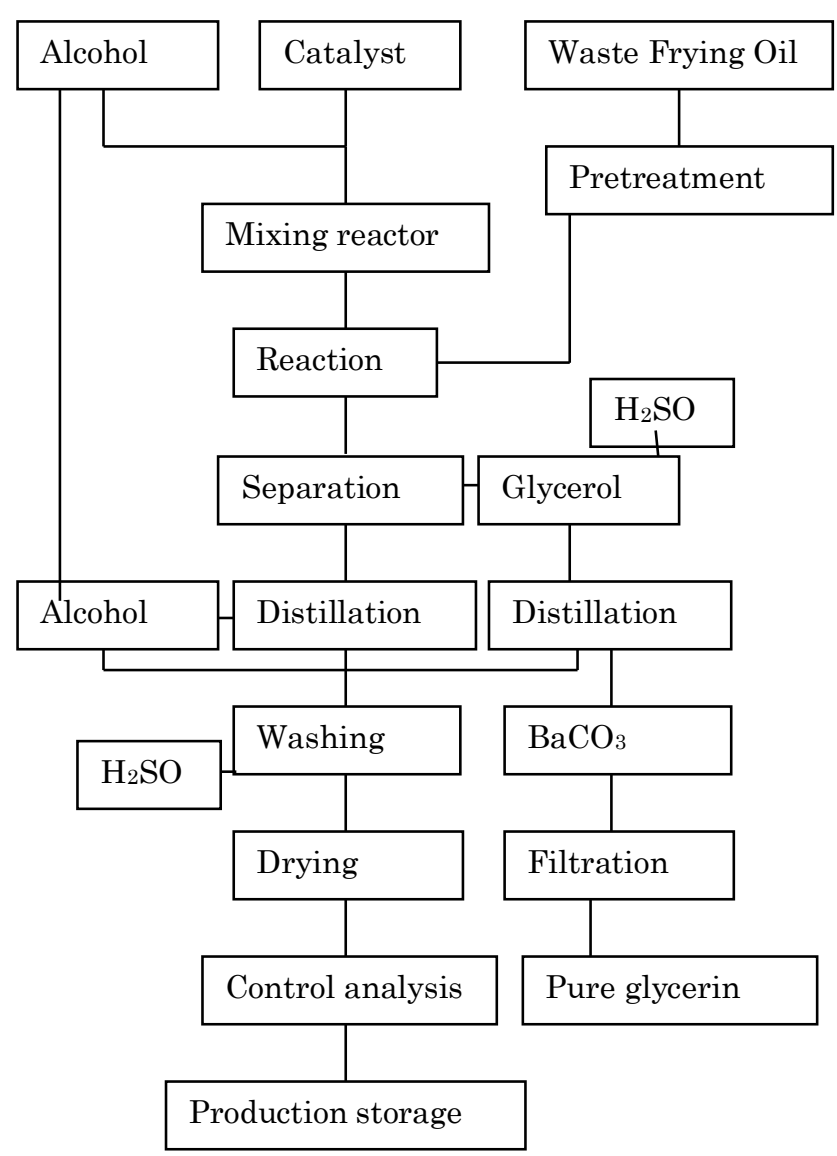

Fig. 1. Flow Chart to Produce Biodiesel and pure glycerin from WFO.

\subsection{Basic - Catalyzed Transesterification Procedure}

A sample of $300(\mathrm{ml})$ of WFO was transferred to a two - neck Woulf flask equipped with a thermometer and reflux condenser. A magnetic bar was used for stirring. $\mathrm{NaOH}$ pellets were completely dissolved in methanol and added to pretreated restaurant waste oil. The mixture was heated until the desired temperature was reached $\left(60^{\circ} \mathrm{C}\right)$, and the transesterification reaction begun. The reactor was kept at around $60{ }^{\circ} \mathrm{C}$ for $2 \mathrm{~h}$. The study was carried out using a methanol/WFO volume ratio which varied from $10 \%$ to $30 \%$ and catalyst quantity equivalent to $0.36-1.44$ wt $\%$ of oil and stirring speed of $600 \mathrm{rpm}$. The scheme of the experimental stand is shown on Fig. 2 with primary vacuum pump. The scheme of the experimental stand without using primary vacuum pump is similar to that of Fig. 2 with exception that thermal treatment is provided under temperature of $125^{\circ} \mathrm{C}$. The same primary vacuum pump used in the WFO pretreatment was used also in biodiesel drying.

\subsection{Purification of Methyl Esters Phase}

At the end of the reaction period $(2 \mathrm{~h})$, the mixture was transferred carefully to a separating funnel to stand there for two hours. The lower layer (glycerol, methanol and most of the catalysts) was drained out. The upper layer (methyl esters, some methanol and traces of the catalyst) was then heated at temperature $100{ }^{\circ} \mathrm{C}$ for $0.5 \mathrm{~h}$ in order to remove the excess of methanol and subsequently cleaned thoroughly by washing with water to provide a purified biodiesel (to bring $\mathrm{pH}$ down to 7). The washed methyl esters were then dried by distillation. 


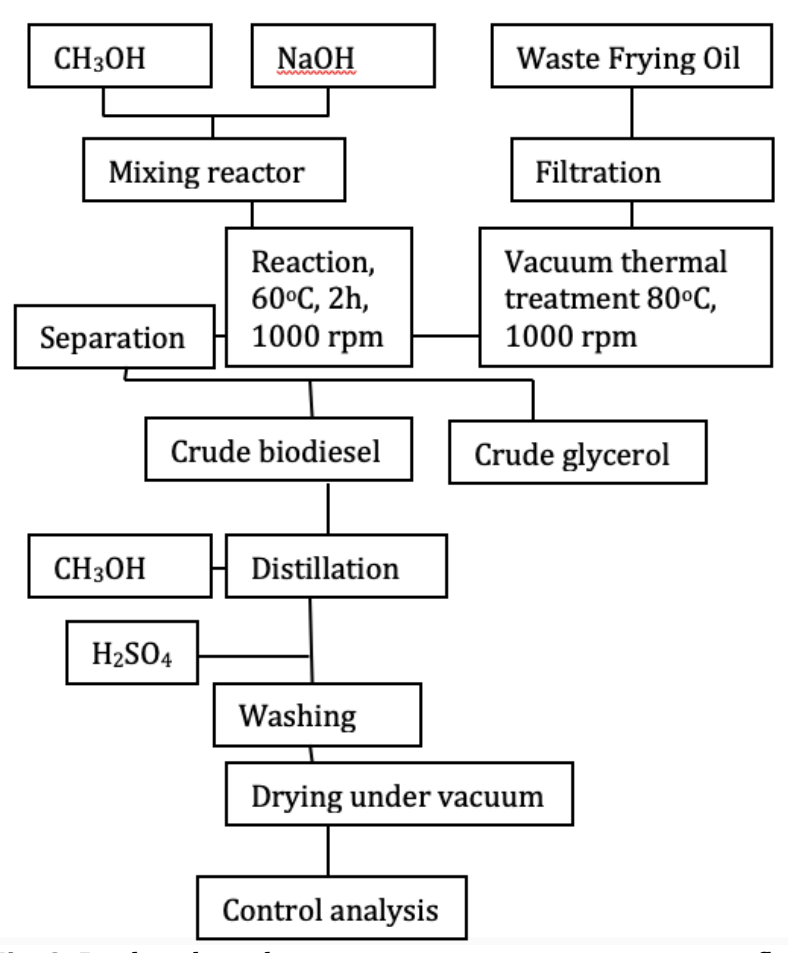

Fig. 2. Biodiesel production using primary vacuum pump flow Chart.

\section{Results and Discussion}

\subsection{WFO and Biodiesel Gas Chromatography Analysis}

GC (gas chromatography) analysis was performed for identifying the hydrocarbon compounds of produced biodiesel. The separation was carried out by using capillary column Rtx-
5MS $30 \mathrm{~m} \times 0.25 \mathrm{~mm}$ ID, $0.25 \mu \mathrm{m}$ with helium at $137.7 \mathrm{ml} / \mathrm{min}$ as a carrier gas and 1:100 split ratio. Fatty acid composition of the waste frying oil is given in Table 1 while the biodiesel composition is given in Table 2. The WFO results are in accordance with those of (Zambiazi, Przybylski, Zambiazi \& Mendonça, 2007), and (Giakoumis, 2013). The little bit differences between the provided compositions of different authors are normal. Hammond et al., (2005) mentioned that fatty acid composition of soybean oil changes considerably with maturity and with seed oil production. In typical soybean triacylglycerols, the palmitate and linolenate tend to decrease with maturity, whereas linoleate increases. Oleate tends to increase to a maximum and then decline slightly. Soybeans selected for a typical fatty acid compositions show quite different patterns.

Tabel 1

Fatty acid composition of waste frying oil (WFO)

\begin{tabular}{lllll}
$\begin{array}{l}\text { Fatty } \\
\text { acid } \\
\text { name }\end{array}$ & Formula & \multicolumn{2}{l}{ Weight (\%) } \\
\cline { 3 - 5 } & & a & b & c \\
\hline Myristic & $\mathrm{CH}_{3}\left(\mathrm{CH}_{2}\right)_{12} \mathrm{COOH}$ & 1.06 & 0.06 & 0.12 \\
Palmitic & $\mathrm{CH}_{3}\left(\mathrm{CH}_{2}\right)_{14} \mathrm{COOH}$ & 12.04 & 9.90 & 11,44 \\
Stearic & $\mathrm{CH}_{3}\left(\mathrm{CH}_{2}\right)_{16} \mathrm{COOH}$ & 3.57 & 3.94 & 4.14 \\
Oleic & $\mathrm{CH}_{3}\left(\mathrm{CH}_{2}\right)_{7} \mathrm{CH}=$ & 21.79 & 21.53 & 23.47 \\
& $\mathrm{CH}_{\left(\mathrm{CH}_{2}\right)_{7} \mathrm{COOH}}$ & & & \\
Linoleic & $\mathrm{CH}_{3}\left(\mathrm{CH}_{2}\right)_{3}(\mathrm{CH} 2 \mathrm{CH}=$ & 54.84 & 56.02 & 53.46 \\
& $\mathrm{CH})_{2}\left(\mathrm{CH}_{2}\right)_{7} \mathrm{COOH}$ & & & \\
Linolenic & $\mathrm{CH}{ }_{3}\left(\mathrm{CH}_{2} \mathrm{CH}=\right.$ & 6.70 & 7.15 & 6.64 \\
& $\mathrm{CH})_{3}\left(\mathrm{CH}_{2}\right)_{7} \mathrm{COOH}$ & & & \\
\hline
\end{tabular}

a)Present work, b) Analysis results taken from (Zambiazi, Przybylski, Zambiazi \& Mendonça, 2007) and c) Analysis results taken from (Giakoumis, 2013).

The biodiesel composition results obtained in the present work (see Table 2) are in accordance with those of (Carvalh et al., 2012) and (Hammond et al., 2005).

Tabel 2

Methyl ester composition produced from waste frying oil (WFO).

\begin{tabular}{|c|c|c|c|c|c|}
\hline \multirow[t]{2}{*}{ Methyl ester } & \multirow[t]{2}{*}{ Formula } & \multicolumn{4}{|c|}{ Weight (\%) } \\
\hline & & $\mathbf{a}$ & b & c & d \\
\hline Myristic & $\mathrm{CH}_{3}\left(\mathrm{CH}_{2}\right)_{12} \mathrm{COO} \mathrm{CH}_{3}$ & 0.06 & - & 0.06 & $0.04 \pm 0.5$ \\
\hline Palmitic & $\mathrm{CH}_{3}\left(\mathrm{CH}_{2}\right)_{14} \mathrm{COO} \mathrm{CH}_{3}$ & 11.30 & 10.7 & 11,4 & $10.57 \pm 0.43$ \\
\hline Stearic & $\mathrm{CH}_{3}\left(\mathrm{CH}_{2}\right)_{16} \mathrm{COO} \mathrm{CH}_{3}$ & 3.64 & 3.3 & 3.2 & $4.09 \pm 0.34$ \\
\hline Oleic & $\mathrm{CH}_{3}\left(\mathrm{CH}_{2}\right)_{7} \mathrm{CH}=\mathrm{CH}\left(\mathrm{CH}_{2}\right)_{7} \mathrm{COO} \mathrm{CH}_{3}$ & 22.37 & 23.5 & 21.2 & $22.98 \pm 2.01$ \\
\hline Linoleic & $\mathrm{CH}_{3}\left(\mathrm{CH}_{2}\right)_{3}(\mathrm{CH} 2 \mathrm{CH}=\mathrm{CH})_{2}\left(\mathrm{CH}_{2}\right)_{7} \mathrm{COO} \mathrm{CH}_{3}$ & 56.15 & 53.6 & 52.5 & $54.51 \pm 1.54$ \\
\hline Linolenic & $\mathrm{CH}_{3}(\mathrm{CH} 2 \mathrm{CH}=\mathrm{CH})_{3}\left(\mathrm{CH}_{2}\right)_{7} \mathrm{COO} \mathrm{CH}_{3}$ & 5.80 & 6.3 & 7.5 & $7.23 \pm 0.78$ \\
\hline
\end{tabular}

a)Present work, b) Analysis results taken from (Carvalh et al., 2012), c) Analysis results taken from (Carvalh et al., 2012) and d) Analysis results taken from (Hammond et al., 2005).

\subsection{The methanol/WFO volume ratio influence}

One of the most important variables affecting the yield of ester is the molar ratio of alcohol to triglyceride (TG) (Peterson\& Scarrah, 1984), and (Schuchardi, Sercheli \& Vargas, 1998). The stoichiometric ratio for transesterification requires 3 moles of alcohol and 1 mole of triglyceride to yield $\mathbf{3}$ moles of fatty acid ester and $\mathbf{1}$ mole of glycerol:

\section{WFO $(\mathrm{TG})+3 \mathrm{CH}_{3} \mathrm{OH} \rightarrow 3$ fatty acid ester +1 glycerol}

The molar ratio is associated with the type of catalyst used. The yield of the reactions is expressed as the mass of methyl esters produced per $100 \mathrm{~g}$ of WFO. The excess of methanol is introduced to ensure the accomplishment of the reaction. But, when considering the weight of methyl ester phase, it contains part of the excess methanol, resulting in more than $100 \%$ of crude yield (fatty acid ester + excess of methanol). (Soulayman, Mustafa \& Hadbah, 2012), used pure (Merck GR) chemicals and found that at constant weight ratio of catalyst/WFO, after $2 \mathrm{~h}$ of reaction the yield increases directly with the excess of methanol up to methanol/WFO volume ratio of $18.17 \%$. When repeating their experiment without removing the excess of methanol from the yield their statement was verified (see Fig. 3). Therefore, this kind of yield could be characterized as crude yield. The dependence of crude yield on methanol/WFO volume ratio, presented in Fig.3, shows that, when excluding the sample with methanol/WFO volume ratio equals to 0.3 (for the oil sample with an acidic value of $0.52 \mathrm{mg} \mathrm{KOH} / \mathrm{g}$ at 0.004 mass ratio of catalyst/WFO) the crude yield of the reactions increases directly with the methanol content increase. Therefore, 
the crude yield was distilled in order to remove the excess of methanol.

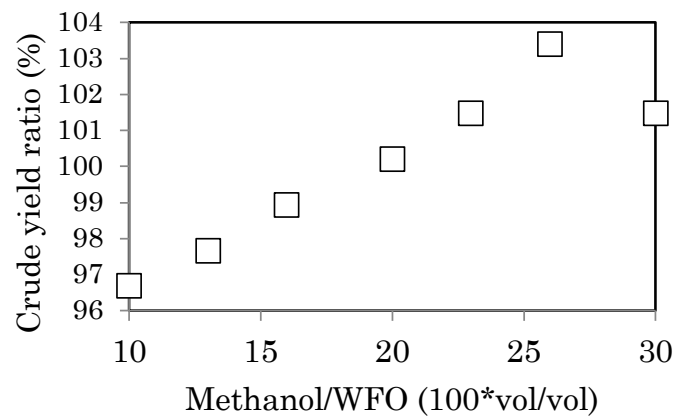

Fig. 3 Influence of the methanol/WFO volume ratio on the crude yield of biodiesel production for catalyst/WFO weight ratio of $0.00367(\mathrm{~g} / \mathrm{ml})$ without methanol excess distillation.

When removing the excess of methanol from the crude yield, it was found that yield, before washing, was constant and equal to 95.73 whatever is the methanol/WFO volume ratio. After washing, the final yield becomes as shown in Fig. 4 where it is seen that methanol/WFO volume ratio of $13 \%$ is the optimum value which leads to maximum real yield (95.09). The methanol/WFO volume ratio of $16 \%$ is also acceptable as it leads to yield of 94.45 .

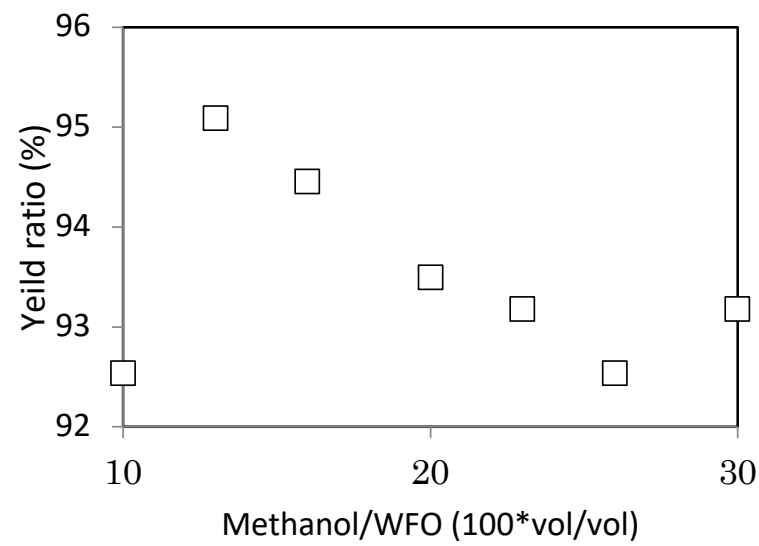

Fig. 4 Influence of the methanol/WFO volume ratio on the yield of biodiesel production for weight catalyst/WFO ratio of $0.00367(\mathrm{~g} / \mathrm{ml})$ with methanol excess distillation and after washing.

\subsection{The $\mathrm{NaOH} / \mathrm{WFO}$ mass Ratio Influence}

The amount of catalyst used in the process is another variable to take into account because it determines the reaction rate, and can cause hydrolysis and saponification. Both reactions interfere with the separation of the glycerol rich phase and with the methyl esters purification. Alkalicatalyzed transesterification is much faster than acidcatalyzed (Freedman, Pryde, \& Mounts, 1984). Sodium hydroxide was chosen in the present work to catalyze the transesterifications because it is the cheapest one and is used widely in large-scale processing. Soulayman, Mustafa \& Hadbah, (2012), stated that, for a WFO with an acidity of $0.52 \mathrm{mg} \mathrm{KOH} / \mathrm{g} \mathrm{WFO}$ and a reaction temperature of $60^{\circ} \mathrm{C}$, the optimal conditions to produce biodiesel by basic - catalyzed transesterification method using pure (Merck, Gr) chemicals are a methanol/WFO volume ratio of $18.17 \%$ and $\mathrm{NaOH} / \mathrm{WFO}$ weight ratio of 0.4 $\%$. When repeating their experiment using commercial grade chemicals and primary vacuum pump additionally, it was found that, for the optimum methanol/WFO volume ratio of $13 \%$, the catalyst quantity is of $0.4 \%$ of oil weight. This result is in a full agreement with that of Soulayman, Mustafa \& Hadbah, (2012). At value lower than $0.4 \%$, the process became unstable. The yield varied by about $3 \%$. At value higher than $0.4 \%$, the yield decreases considerably (see Table 3).

Tabel 3

The effect of $\mathrm{NaOH}$ catalyst on WFO transesterification.

\begin{tabular}{llll}
$\begin{array}{l}\text { NaOH } \\
\text { mass } \\
(\mathbf{g})\end{array}$ & $\begin{array}{l}\text { Crude } \\
\text { yield } \\
\text { (ml) }\end{array}$ & $\begin{array}{l}\text { Yield after excess } \\
\text { methanol removal } \\
(\mathbf{m l})\end{array}$ & $\begin{array}{l}\text { Yield after } \\
\text { Washing } \\
(\mathbf{m l})\end{array}$ \\
\hline 1 & 304 & 300 & 290 \\
1 & 315 & 300 & 295 \\
1 & 300 & 297 & 289 \\
1.1 & 306 & 300 & 298 \\
1.1 & 307 & 301 & 294 \\
1.1 & 308 & 300 & 295 \\
1.2 & 300 & 297 & 285 \\
1.2 & 298 & 294 & 282 \\
1.2 & 299 & 294 & 283 \\
\hline
\end{tabular}

Used values are: $300 \mathrm{ml} W F O, 40 \mathrm{ml} \mathrm{CH}_{3} \mathrm{OH}$, reaction time $2 \mathrm{~h}$.

It should be noted that, soaps formed during base catalyzed transesterification were eliminated by applying sulfuric acid after the transesterification completed. This procedure simplifies also the separation of the product phases and prevents the formation of emulsions if a water wash operation is used for the finished fuel. Finally, the optimization data clearly demonstrated the evidence that the transesterification reaction can be accelerated by increasing the reaction temperature, and increasing the amount of base catalyst. For reactions occurring at atmospheric pressure, the temperature is limited by the boiling point of methanol $\left(64.6^{\circ} \mathrm{C}\right)$, with the highest temperature used in this study being $60^{\circ} \mathrm{C}$. Increasing the amount of base catalyst will increase soap formation, but as noted previously, these soaps can be eliminated by using sulfuric acid in a second processing step.

\subsection{The effect of reaction time}

When studying the influence of reaction time on the reaction productivity, it was found (see Fig. 5) that the conversion rate increases with reaction time. Moreover, the influence of reaction period is less important when period exceeds 75 minutes while it is very important at lower periods.

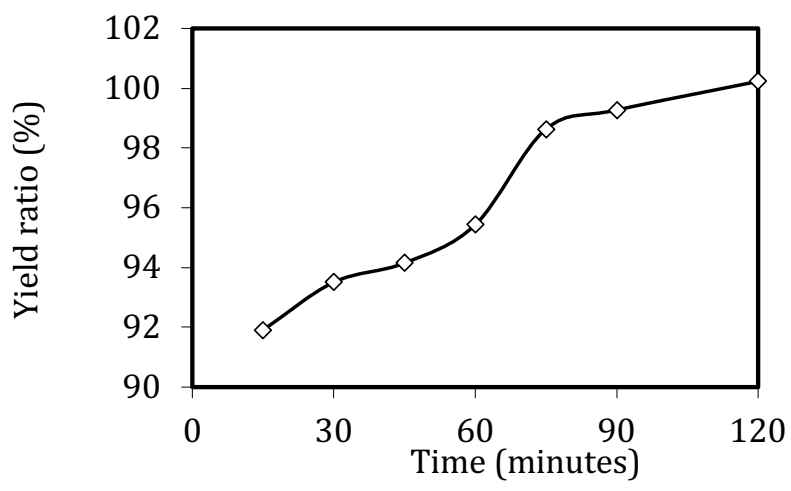

Fig. 5 The effect of reaction time on yield. 
However, the production scale and the economical feasibility give the main data for determining the suitable time reaction period from production point of view. Under the condition of methanol to oil ratio of $6: 1,1 \%$ sodium hydroxide catalyst and $60^{\circ} \mathrm{C}$, the refined soybean oil was transesterified (Freedman, Pryde, \& Mounts, 1984). After $1 \mathrm{~h}$, the conversion rate was $94 \%$. The result of the present work is in accordance with that of (Freedman, Pryde, \& Mounts, 1984).

\subsection{Biodiesel Characterization}

In order to verify the quality of the biodiesel produced under different experimental conditions, the properties of the obtained biodiesel were compared with the specifications of the standard EN 14214 (2003). So, several samples of biodiesel were submitted to a series of tests. Table 4 gives the obtained results of some samples at more preferable conditions regarding esters concentration (\%wet), density at $15{ }^{\circ} \mathrm{C}\left(\mathrm{g} / \mathrm{cm}^{3}\right)$, kinematic viscosity at 40 ${ }^{\circ} \mathrm{C}\left(\mathrm{mm}^{2} / \mathrm{s}\right)$ and iodine value $(\mathrm{gI} / 100 \mathrm{~g})$ while Table 5 gives the obtained results regarding acid value (mg KOH/g), water content $(\% \mathrm{wt})$, sodium content $(\mathrm{mg} / \mathrm{kg})$, methanol content (\% wet) and Flash point $\left({ }^{\circ} \mathrm{C}\right)$ of the produced biodiesel. The obtained results show that for all the studied conditions, the biodiesel produced in the present study has a density of $0.88 \mathrm{~g} / \mathrm{cm}^{3}$. The methanol content in the produced samples was 0.002 (\%wt) while the standard EN 14214 (2003) allows the max value of 0.2 (\%wt).

Table 4

Some physical properties of the produced biodiesel.

\begin{tabular}{|c|c|c|c|c|}
\hline $\begin{array}{l}\text { Sample } \\
\text { number }\end{array}$ & $\begin{array}{l}\text { Esters } \\
\text { Concentration } \\
\text { (\%wet) }\end{array}$ & Density at $15{ }^{\circ} \mathrm{C}\left(\mathrm{g} / \mathrm{cm}^{3}\right)$ & $\begin{array}{l}\text { Cinematic } \\
\text { viscosity at } 40{ }^{\circ} \mathrm{C}\left(\mathrm{mm}^{2} / \mathrm{s}\right)\end{array}$ & $\begin{array}{l}\text { Iodine } \\
\text { value }(\mathrm{gI} / \mathbf{1 0 0 g})\end{array}$ \\
\hline 1 & 98.73 & 0.88 & 4.94 & 129.6 \\
\hline 2 & 99.15 & 0.88 & 4.59 & 129.7 \\
\hline 3 & 99.17 & 0.88 & 4.51 & 128.7 \\
\hline 4 & 98.79 & 0.88 & 4.44 & 128.3 \\
\hline 5 & 98.46 & 0.88 & 4.33 & 128.8 \\
\hline standards & Min. 96.5 & $0.86-0.9$ & $3.5-5$ & Less than 120 \\
\hline
\end{tabular}

Table 5

Some other physical properties of the produced biodiesel.

\begin{tabular}{lllll}
$\begin{array}{l}\text { Sample } \\
\text { number }\end{array}$ & $\begin{array}{l}\text { Acid value }(\mathbf{m g} \\
\text { KOH/g) }\end{array}$ & Water content $(\%$ wet) & Sodium content $(\mathbf{m g} / \mathbf{k g})$ & Flash point $\left({ }^{\circ} \mathbf{C}\right)$ \\
\hline 1 & 0.20 & 0.042 & 1.3 & 184 \\
2 & 0.27 & 0.037 & 2.0 & 182 \\
3 & 0.21 & 0.033 & 2.0 & 182 \\
4 & 0.30 & 0.038 & 3.0 & 182 \\
5 & 0.34 & 0.035 & 2.8 & 182 \\
standards & Max. 0.5 & Max.0.05 & Max.5 & $>120$ \\
\hline
\end{tabular}

\subsection{Acid Pre-treatment Effectiveness}

Acid pre-treatment is used to reduce free fatty acids FFA. In order to determine the influence of acid pre-treatment process on the crude yield this method was applied on WFO of different acid values. Thus an acid-catalyzed pretreatment process before the base-catalyzed transesterification process was applied. In order to compare the influence of applying (1) Basic - catalyzed transesterification and (2) Acid pre-treatment - Basic catalyzed transesterification processes on the biodiesel productivity, the above mentioned two processes were applied using the same experimental variables except adding $\mathrm{H}_{2} \mathrm{SO}_{4}$ quantity.).

Table 6

The effect of acid pre-treatment on the crude yield.

\begin{tabular}{lc}
\hline $\mathrm{H}_{2} \mathrm{SO}_{4}(\mathrm{ml})$ & Biodiesel $(\mathrm{ml})$ \\
\hline 0 & 308 \\
0.3 & 296 \\
0.6 & 298 \\
1.0 & 302 \\
\hline
\end{tabular}

Used values are: $300 \mathrm{ml} \mathrm{WFO}, 40 \mathrm{ml} \mathrm{CH} 3 \mathrm{OH}$, reaction time $2 \mathrm{~h}$. acid value 0.52

The results are given in Table 6. In this context, when repeating the same series of experiments with changing the WFO acid value, it was found that for WFO of acid value less than 1 the basic - catalyzed transesterification is preferable from industrial and economical point of view even it was recommended that $0.5-1.5 \%$ (based on the weight of free fatty acid in the oil) of pure (95-98\%) sulphuric acid should be used as a catalyst (Abdullah, Hasan and Yusoff, 2013)

\section{Pilot Production Unit}

Most researchers have selected the cheapest and simplest technique of biodiesel production. Others have applied the expensive methods once the untreated oil was used as feedstock of biodiesel. However, in commercial processes, highly refined vegetable oils, consisting primarily of triglycerides (TGs) and typically used as feedstocks, are transesterified with low molecular weight alcohols, e.g. methanol and ethanol, using homogeneous alkali catalysts (such as $\mathrm{NaOH}$ and $\mathrm{KOH}$ ). To be more economically viable, the use of virgin oils accounting for $88 \%$ of the total estimated biodiesel production cost, could be replaced with a more economical feedstock, such as waste fats and oils that contain a low to moderate amount of free fatty acids (FFAs), moisture and other impurities (Ferreira, Cardoso $\&$ da Silva, 2012). Even though, the economical impact is highly related to the biodiesel production technique. Therefore, the quality of biodiesel should be taken into account when any of the techniques reported by (Jain and Sharma, 2010) is applied. It is due to the operational process may take place either with catalysts such as alkaline (Meher, Dharmagadda \& Naik, 2006), acid, (Lotero et al.. 2005), and enzyme (Noureddini, Gao and Philkana, 2005, Soumanou and Bornscheuer, 2003), or 
without catalysts (Madras, Kolluru and Kumar, 2004). In an industrial scale, the alkaline catalyst is the most preferable way due to low cost, ease of installation and above all, its high reaction rate without requiring a large reactor volume and saving the production fixed capital (Berrios, Martín, Chica and Martín, 2010).

The recent increase in the world biofuels demand, along with the need to reduce costs while improving the environmental sustainability of the biodiesel production, have led to the search for catalysts that should be economically viable, efficient, and environmentally friendly. In this context, a pilot production unit has been designed and constructed. This unit operates with WFO feedstock and commercial grade chemicals. Fig. 1 describes the processing steps and methods used to produce biodiesel and pure glycerine from WFO with the production capacity of 400 l/day.

The first main step in the used process is the chemical analysis of the weekly gathered quantity of WFO in order to determine the acid value of the free fatty acid content and to apply the suitable WFO pre-treatment. The acid value of the WFO was determined in order to estimate the free fatty acid content and give an idea of how much acid catalyst and methanol would be needed to push the acid esterification chemical towards methyl ester production. Karmee, Patria \& Lin, (2015), reported the economic analyses of the biodiesel production from waste cooking oil in Hong Kong with different catalysts using Aspen Plus as simulation tool. As the economic feasibility of the pilot unit is out of the frames of the present work some comments regarding WFO pretreatment and production results will be provided below. The detailed cost analysis of the pilot production unit will be given elsewhere.

\subsection{WFO Pre-treatment}

The pre-treatment stage in the pilot unit consist of solid particles removal and water separation always while the application of acid catalyzed pre-esterification depends on the WFO acid value. If acid value is less than 1.5, the acid esterification is not required. So, as the acid value of the used raw materials of WFO was less than 1 over three years of operation, the description of the pre-treatment stage will be restricted to particles removal and water separation.

\subsection{Production Conditions}

The biodiesel production capacity is $400 \mathrm{l} /$ day. The reaction conditions are kept in optimum conditions, such as the reaction temperature at $60^{\circ} \mathrm{C}$. The volume ratio of methanol to WFO was $13 \%$ and mass ratio of $\mathrm{NaOH}$ to WFO is $0.4 \%$. The reaction time was $2 \mathrm{~h}$. As the acid value of the used WFO is always less than 1 the acid pretreatment is not required. In these optimum conditions the biodiesel conversion is $100 \%$ approximately. The daily obtained results with regards to local prices of 2012 demonstrate the economical feasibility of continuous pilot biodiesel production.

\subsection{Production Results}

In the pretreatment process, the solid particles removal is provided manually where the same container plays the role of decanter to separate the WFO from the water while the rest moisture removal is provided under primary vacuum in heater with a mixing ratio of 200rpm. The suitable quantities of methanol and catalyst $\mathrm{NaOH}$ are reacted to produce methoxide in a special reactor with a mixing ratio of $200 \mathrm{rpm}$. The pre-treated WFO as well as the produced methoxide are then transferred into the reactor with a mixing ratio of 800rpm in which the WFO will be transesterified with methoxide. The reaction mixture of this process is decanted in a special decanter. The byproduct glycerol is filtered and transferred to a special decanter, leaving the biodiesel, base catalyst $(\mathrm{NaOH})$, and remaining glycerol in the filtrate which will be transferred into a distillation column with a mixing ratio of 800rpm for excess methanol distillation which in its turn transferred to the methanol storage while the rest is transferred to a special decanter with a mixing ratio of 200rpm for washing with water after adding some drops of $\mathrm{H}_{2} \mathrm{SO}_{4}$. A stream of water and the filtrate are transferred into extraction column. The remaining methanol, $\mathrm{KOH}$, and remaining glycerol are extracted by water, while the biodiesel is separated. Then the biodiesel is transferred into a distillation column with a mixing ratio of $800 \mathrm{rpm}$ to dry it by removing the remaining moisture. The obtained pure biodiesel is then stored in the biodiesel tank.

On the other hand, all the remaining substances such as $\mathrm{WFO}$, methanol, glycerol, and $\mathrm{NaOH}$ in the reaction are transferred into a special reactor for the neutralization process where a suitable quantity of $\mathrm{H}_{2} \mathrm{SO}_{4}$ is added. After $12 \mathrm{~h}$ of neutralization the remaining WFO is decanted; while the remaining methanol, glycerol and water are transferred into two separated distillation columns: one for extracting methanol and transferring it to the methanol storage while the other for water extraction. A suitable quantity of $\mathrm{BaCO} 3$ is added to the water-free and methanol-free glycerol for $\mathrm{H}_{2} \mathrm{SO}_{4}$ removal. The obtained pure glycerol after filtration is then stored in a tank.

\section{Conclusion}

The present work allows achieve the following results:

- The production of biodiesel from WFO is feasible by basic catalyzed transesterification.

- The determined best working conditions for basic catalyzed transesterification biodiesel production from WFO as follows: primary vacuum pump pretreatment, $2 \mathrm{~h}$ of reaction, a methanol/WFO volume ratio of $13 \%$ and a catalyst/WFO weight ratio of $0.4 \%$.

- A good agreement with available data is observed.

- The realization of efficient separation/purification of methyl asters phase

- The design and construction of biodiesel production educational pilot facility of $4001 /$ day production capacity that meets the specifications of EN 14214.

\section{Acknowledgments}

The authors wish to thank Dr. R. Jabra for useful discussions and English reviewing.

\section{References}

Barzegarian, R., Keshavarz Moraveji, M. \& Aloueyan, A. (2016) Experimental investigation on heat transfer characteristics and pressure drop of BPHE (brazed plate heat exchanger) using $\mathrm{TiO}_{2}$-water nanofluid. Experimental Thermal and Fluid Science, 74, 11-18. 
Behrangzadeh, A. \& Heyhat, M.M. (2016) The effect of using nano-silver dispersed water based nanofluid as a passive method for energy efficiency enhancement in a plate heat exchanger. Applied Thermal Engineering, 102, 311-317.

Han, X.H., Cui, L.Q., Chen, S.J., Chen, G.M. \& Wang, Q. (2010) A numerical and experimental study of chevron, corrugatedplate heat exchangers. International Communications in Heat and Mass Transfer, 37, 1008-1014.

Holman, J. P. (2001) Experimental Methods for Engineers (7th edition). New York: McGraw-Hill.

Huang, D., Wu, Z. \& Sunden, B. (2016) Effects of hybrid nanofluid mixture in plate heat exchangers. Experimental Thermal and Fluid Science, 72, 190-196.

Kabeel, A E, El Maaty, T.A, \& El Samadony, Y. (2013) The effect of using nano-particles on corrugated plate heat exchanger performance. Applied Thermal Engineering, 52, 221-229.

Kakaç S., Liu H. \& Pramuanjaroenkij A. (2012) Heat Exchangers: Selection, Rating, and Thermal Design. Florida, USA: CRC Press.

Kan, M., Ipek, O. \& Gurel, B. (2015) Plate heat exchangers as a compact design and optimization of different channel angles, Acta Physica Polonica, 12, 49-52.

Kumar, V., Tiwari A. K., \& Ghosh, S.K. (2016). Effect of chevron angle on heat transfer performance in plate heat exchanger using $\mathrm{ZnO} /$ water nanofluid, Energy Conversion and Management, 118, 142-154.

Pandey, S.D. \& Nema, V.K. (2012) Experimental analysis of heat transfer and friction factor of nanofluid as a coolant in a corrugated plate heat exchanger, Experimental Thermal and Fluid Science, 38, 248-256.

Sarafraz, M. \& Hormozi, F. (2016) Heat transfer, pressure drop and fouling studies of multiwalled carbon nanotube nanofluids inside a plate heat exchanger. Experimental Thermal and Fluid Science, 2016, 72, 1-11.

Serebryakova, M.A. Dimov, S.V., Bardakhanov, S. P. \& Novopashin, S. A. (2015) Thermal conductivity, viscosity and rheology of a suspension based on $\mathrm{Al}_{2} \mathrm{O}_{3}$ nanoparticles and mixture of $90 \%$ ethylene glycol and $10 \%$ water, International Journal of Heat and Mass Transfer, 83, 187-191.

Taghizadeh-Tabari, Z., Zeinali Heris, S., Moradi, M. \& Kahani, M. (2016) The study on application of $\mathrm{TiO}_{2} /$ water nanofluid in plate heat exchanger of milk pasteurization industries. Renewable and Sustainable Energy Reviews, 58, 1318-1326.

Tiwari, A.K., Ghosh, P. \& Sarkar, J. (2013). Performance comparison of the plate heat exchanger using different nanofluids. Experimental Thermal and Fluid Science, 49, 141-151.

Tiwari, A.K., Ghosh, P., Sarkar, J., Dahiya, H. \& Parekh, J. (2014) Numerical investigation of heat transfer and fluid flow in plate heat exchanger using nanofluids. International Journal of Thermal Sciences, 85, 93-103.

Yang, J., Jacobi, A. \& Liu, W. (2017) Heat transfer correlations for single-phase flow in plate heat exchangers based on experimental data. Applied Thermal Engineering, 113, 15471557. 